\title{
PRÁTICAS ARQUEOLÓGICAS EM COMUNIDADE Experiências Participativas na Chapada Diamantina, no Âmbito do Projeto Circuitos Arqueológicos de Visitação
}

\author{
ARCHAEOLOGICAL PRACTICES IN THE COMMUNITY \\ Participative Experiences in the Diamantine Plate, in the \\ Framework of the Archaeological Visitation Circuits Project
}

\author{
Carlos Alberto Etchevarne ${ }^{1}$ \\ etchevarnebahia@gmail.com / https://orcid.org/0000-0003-2817-5788 \\ Alvandyr Dantas Bezerra ${ }^{2}$ \\ alvandyr123@gmail.com /https://orcid.org/0000-0001-8778-5784
}

\section{RESUMO}

As práticas sociais desenvolvidas no âmbito do "Projeto Circuitos Arqueológicos de Visitação da Chapada Diamantina/Bahia" enquadram-se nos pressupostos da chamada Arqueologia Pública. Os resultados da vivência efetivada nos seis municípios chapadenses contemplados (Iraquara, Lençóis, Morro do Chapéu, Palmeiras, Seabra e Wagner), deixam transparecer a importância do compromisso social quando a prática arqueológica é desenvolvida em contextos comunitários, nesse caso, em localidades situadas próximas aos sítios de arte rupestre. Trata-se, por conseguinte, de uma reflexão sobre a natureza transformadora da Arqueologia através da interação social e troca de saberes.

Palavras chave: Circuitos arqueológicos; Arte Rupestre; Arqueologia Comunitária.

${ }^{1}$ Departamento de Antropologia, UFBA.

${ }^{2}$ Discente, Programa de Pós-Graduação em Arqueologia e Patrimônio Cultural, UFRB. 


\title{
Clio Arqueológica 2021, V36N1, p.42-76, ETCHEVARNE; BEZERRA \\ DOI: 10.51359/2448-2331.2021.250744
}

\begin{abstract}
The social practices developed within the scope of the "Chapada Diamantina / Bahia Archaeological Visitation Project" fit the premises of the so-called Public Archeology. The results of the experience carried out in the six contemplated Chapada municipalities (Iraquara, Lençóis, Morro do Chapéu, Palmeiras, Seabra and Wagner), reveal the importance of social commitment when the archaeological practice is developed in community contexts, in this case, in locations located close by to rock art sites. It is, therefore, a reflection on the transformative nature of Archeology through social interaction and exchange of knowledge.
\end{abstract}

Keywords: Archaeological circuits; Rock Arte; Community Archeology.

\section{CONTEXTO DA PESQUISA}

A inserção do trabalho do arqueólogo dentro de comunidades tem permitido diversas reflexões sobre a relação entre o pesquisador e as pessoas que residem no entorno dos sítios arqueológicos, demonstrando a consolidação da ideia de que as pesquisas, desenvolvidas em conjunto com moradores locais, possibilita uma nova percepção neles, acerca dos sítios arqueológicos, que podem redundar na própria preservação dos mesmos. Essa relação de perceptibilidade dos locais arqueológicos que se instala, via a pesquisa, induz a novas caracterizações territoriais e posicionamentos espaciais referenciais, no plano simbólico e no prático, construídos pelos próprios habitantes vizinhos aos sítios. Dessa percepção podem derivar estímulos para a conservação e uso dos locais, que ficariam assim, envolvidos na esfera reconhecível do universo do cotidiano. 
Para que essa relação de perceptibilidade seja continuada, deve existir um motivo significativo interno que supere as valorizações externas ao grupo, que poderiam impor conotações qualitativas diferentes. As práticas arqueológicas com as comunidades devem respeitar certas condições sine qua non com relação aos conhecimentos tradicionais com as informações proporcionadas sobre os sítios, tendo um valor equivalente àqueles dos pesquisadores. Ou seja, deve se promover um momento de transferência de saberes que será destacado e suficientemente trabalhado.

Ao mesmo tempo, precisa se demonstrar que os sítios arqueológicos podem ser configurados como marcos físicos de reflexão sobre os processos históricos havidos nos mesmos lugares em que os membros das comunidades habitam hoje, de forma a que se torne evidente que eles também estão inseridos dentro desses processos, como representantes contemporâneos.

Por outro lado, devem ser priorizados os aspectos econômicos que podem estar associados ao uso dos sítios com pinturas rupestres. Normalmente o entorno social desses locais arqueológicos está composto por grupos familiares, com condições econômicas restritivas e, em alguns casos, com carência de recursos básicos. De modo, que os programas de pesquisa com locais de pinturas rupestres devem redundar em alguma forma de benefício social. A própria preservação dos espaços rupestres pintados depende do uso racional e adequado e não da proibição do acesso a eles. 
Ou seja, as práticas arqueológicas devem ter como objetivo social promover melhoras às condições de subsistência dos grupos vizinhos aos sítios. Isto implica, necessariamente, que o pesquisador deve convocar à comunidade e trabalhar em conjunto. O produto dessa convocação tem de ser o resultado de uma atividade participativa, onde os benefícios de caráter econômico e social, não podem alterar, em essência, o modo de vida e a forma de ser dos grupos sociais. Dessa maneira, os programas arqueológicos precisam ser adaptados à realidade local, respeitando seu cotidiano.

$\mathrm{Na}$ atualidade, as relações entre pesquisadores e comunidades são contempladas dentro do amplo universo daquilo que se denomina Arqueologia Pública (Boado, 2012). Essa vertente de atuação está relacionada à maior visibilidade e protagonismo do contexto histórico e social contemporâneo, na produção das informações arqueológicas e o reconhecimento dos arqueólogos de sua intransferível missão no comprometimento com os grupos sociais. Como aponta Desiderio Vaquerizo,

la Public Archaeology parte, precisamente, de implicar a la ciudadanía en el proceso cientifico, entendido éste desde la fase de registro propiamente dicho (prospección, excavación, documentación o simple estudio de materiales), hasta que las estructuras, los artefactos y los ecofactos obtenidos son interpretados, conservados si procede, difundidos y también rentabilizados en sentido amplio. Todo ello desde un punto de partida indiscutible: que nuestra materia une a su componente histórico otro patrimonial y, en consecuencia, dadas sus evidentes potencialidades de mercado, además de conocimiento y capacidad de formación incorpora a 
su esencia como ciencia un componente emocional y estético, un valor simbólico destacado, y la posibilidad nada desdeñable en los tiempos que corren de generar retorno económico, en una auténtica cadena de valor que ciudades, (Vaquerizo, 2017, pag. 265).

A grosso modo, então, a Arqueologia Pública é entendida como a prática que promove a interação de qualquer pesquisa com as pessoas não especialistas, com a finalidade de fazer uma arqueologia voltada para todos. Dentro desse campo genérico, cabe ainda, especificar mais a atuação, conforme os sujeitos a quem está destinado, os aportes metodológicos e recortes territoriais. Assim, surgem classificações como a denominada Arqueologia Comunitária ou Colaborativa que se caracteriza por ter preocupação especial com as comunidades existentes entorno dos sítios arqueológicos, ouvir suas vozes e incluí-las no processo de construção de informações.

Como principal premissa da Arqueologia Comunitária, os grupos sociais circunvizinhos aos sítios arqueológicos poderão ser importantes aliados na proteção dessas áreas. Um exemplo dessa integração da comunidade com os territórios arqueológicos foi o projeto de atuação desenvolvido nas Cuevas de las Maravillas e Cueva Borbón, na República Dominicana, apresentado por Griffith e Griffith (2012), em que a população local teve um importante papel na viabilização da atividade da pesquisa, sendo integrada à gestão do patrimônio e ao desenvolvimento do turismo. A população foi qualificada, visando à valorização dos dois sítios e 


\section{Clio Arqueológica 2021, V36N1, p.42-76, ETCHEVARNE; BEZERRA} DOI: 10.51359/2448-2331.2021.250744

fortalecendo o sentimento de coletividade, tornando-se capaz de divulgar uma história própria, sem a necessidade de uma atuação contínua de especialistas.

Por isso, a Arqueologia Comunitária deve atuar com uma metodologia adequada para considerar o trabalho com os não especialistas. Deve-se buscar alternativas que não sejam as verticalistas e unilaterais, que se apoiam, apenas, nas políticas de preservação dos órgãos oficiais especializados. Obviamente, as metodologias de atuação da arqueologia comunitária não deverão ser iguais para todos os contextos sociais, mas, pelo contrário, devem variar e respeitar as especificidades culturais das comunidades e os problemas de pesquisa atinentes a cada área de estudo. O que deve se manter como base intrínseca a todo projeto é o foco nos grupos sociais contemporâneos e sua relação com os locais arqueológicos.

Os trabalhos arqueológicos com essa perspectiva social iniciaram-se na década de 1970 (Lumbreras,1981), mas somente vêm crescendo nos últimos tempos, em diferentes partes do mundo. Basta aqui mencionar, o caso de Água Blanca, em Equador, no interior de um Parque Nacional, em que a participação da comunidade nos projetos de pesquisa e de proposta de gestão, deu subsídios suficientes para a justificativa de permanência dela dentro do parque. Maria Luz Endere e Maria Laura Zulaica, fazem referência ao trabalho dos arqueólogos Colin Mc Ewan e Maria Isabel Silva que pesquisaram durante 5 anos junto à comunidade, 


\section{Clio Arqueológica 2021, V36N1, p.42-76, ETCHEVARNE; BEZERRA DOI: 10.51359/2448-2331.2021.250744}

Lo que resulta relevante es que llevaron a cabo una investigación que ellos califican como "arqueologia participativa" con la comunidade. Los comuneros fueron empleados y entrenados para excavar, levantar mapas topográficos, y procesar el material post excavación. Las principales decisiones estratégicas fueron discutidas y consensuadas con la comunidad. (Endere e Zulaica, 2015, p. 272).

Com esse norte, no âmbito do Projeto dos Circuitos Arqueológicos de Visitação da Chapada Diamantina, Bahia (de aqui para a frente apenas Circuitos Arqueológicos) realizou-se uma série de ações sociais programadas paralelamente às pesquisas arqueológicas realizadas na região de seis municípios chapadenses (Iraquara, Lençóis, Morro do Chapéu, Palmeiras, Seabra e Wagner) e que se enquadra nas práticas sociais da Arqueologia Comunitária, que considera todo o processo de produção científica arqueológica como peça fundamental no diálogo simétrico com as comunidades locais, tendo um papel preponderante no fortalecimento do sentimento de topofilia e, consequentemente, na valorização das identidades coletivas e territoriais.

As ações do projeto concentraram seus esforços, no início, na identificação e aproximação com os representantes comunitários de seis municípios da região da Chapada Diamantina que contribuíram na preparação de reuniões, seminários, encontros e visitas de campo. A partir dessa etapa, as consequentes atividades e produtos foram refletidos, discutidos e organizados com o maior número possível de pessoas, admitindo-se reconsiderações ou novos rumos e tiveram como eixo a pesquisa, preservação e uso sustentável dos sítios arqueológicos de arte rupestre. 


\section{PROJETO CIRCUITOS ARQUEOLÓGICOS DE VISITAÇÃO DA CHAPADA DIAMANTINA}

O território da Chapada Diamantina, localizado no estado da Bahia, apresenta do ponto de vista do universo arqueológico um vasto e rico conjunto de sítios, que são elementos testemunhais sobre a presença humana nessa região, antes da chegada dos colonizadores e em período pós-colonial (século XIX). Este aspecto documental se reveste de grande importância, pois, são vestígios conservados e interpretados em momentos posteriores à sua execução, uso e abandono, que permitem, no que for possível, a reconstrução histórica e cultural dos grupos que os conceberam.

A integridade deste universo de vestígios arqueológicos vem sendo ameaçada, progressiva e aceleradamente, pelo avanço descontrolado de projetos econômicos que alteram radicalmente a paisagem natural e cultural tradicional. Efetivamente, enquanto as atividades produtivas associadas a uma economia de subsistência de caráter familiar permitiram até recentemente a conservação do entorno e os próprios sítios arqueológicos, a introdução de novas formas de exploração do ambiente, de maneira intensiva e a grande escala, provocam perturbações dos contextos dos sítios, quando não a própria eliminação deles. 
Algumas ações de preservação vêm sendo executadas, por parte de pesquisadores do Grupo de Pesquisa Bahia Arqueológica ${ }^{3}$ têm dedicado esforços, desde 1998, em duas tarefas básicas que são a de identificação e registro, por um lado, e a de sensibilização e capacitação comunitária, por outro. Se por um lado, nestes anos de trabalho conseguiu-se formar um banco de dados importante sobre sítios arqueológicos, principalmente de arte rupestre da Chapada Diamantina, por outro, e não menos importante, formou-se uma consciência crítica e uma atitude sensível para com esses monumentos arqueológicos.

A região da Chapada Diamantina, devido a seu potencial de abrigos e paredões pintados e gravados, foi escolhida para um projeto denominado Circuitos Arqueológicos de Visitação, cuja realização ocorreu a partir da parceria entre o Instituto do Patrimonio Artístico e Cultural (IPAC) e a Universidade Federal da Bahia (UFBA), iniciado em 2008 durante o Fórum do Patrimônio Material, realizado na cidade de Lençóis, na Bahia. Nesse evento foi assinado um termo de cooperação entre as duas instituições e no final de 2009, começa a ser colocado em prática o Programa de Pesquisa e Manejo de Sítios de Arte Rupestre em seis municípios localizados na região da Chapada Diamantina. Durante o desenvolvimento desse programa concebeu-se a continuidade com o projeto

\footnotetext{
${ }^{3}$ O Grupo de Pesquisa Bahia Arqueológica está vinculado à Universidade Federal da Bahia e é reconhecido pelo CNPq. Tem como propósito divulgar as pesquisas realizadas pelo grupo e os seus resultados, para a comunidade científica e o público em geral.
} 
"Circuitos Arqueológicos", de longa duração, contemplando seis municípios:

Iraquara, Lençóis, Morro do Chapéu, Palmeiras, Seabra e Wagner.

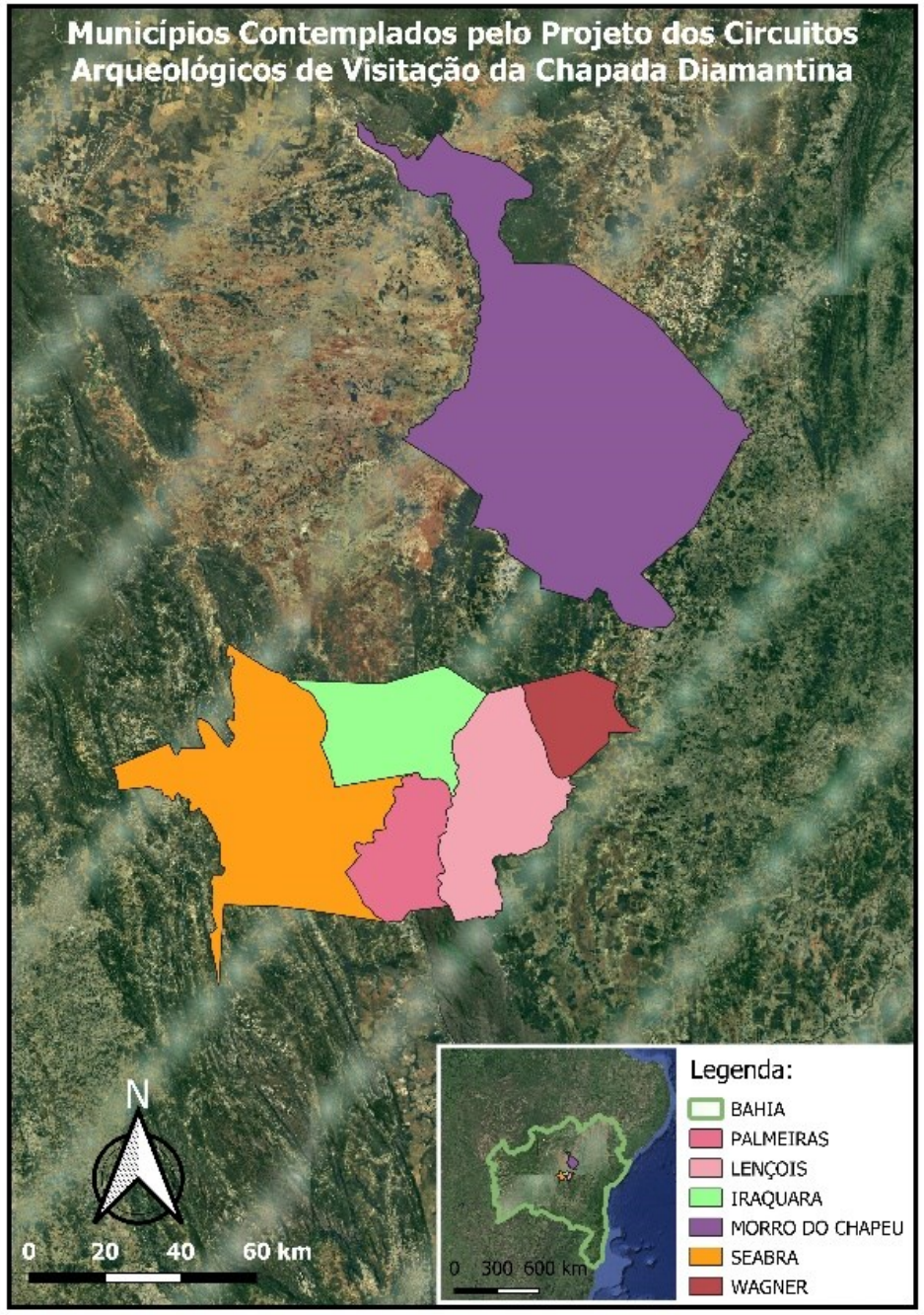

Figura 1. Localização dos seis municípios contemplados pelo Projeto, na região da Chapada Diamantina. 
O principal objetivo do projeto Circuitos Arqueológicos foi dar início à instauração de uma ação permanente entre pesquisadores da UFBA e do IPAC, conjuntamente com as prefeituras municipais e, muito especialmente, com as comunidades em que os sítios rupestres se encontram. Partiu-se do princípio de que somente com o envolvimento de todos, haveria um efetivo programa de preservação e gestão dos sítios de pinturas e gravuras rupestres, assim como de outros conjuntos arqueológicos.

As premissas que direcionam as ações foram definidas pela premência em atuar no que se refere à preservação, estudo e gestão de sítios pré-coloniais, em lugares onde as instâncias administrativas, federais, estaduais e municipais, são inexistentes ou, então, de tênue presença.

A primeira e a mais importante das premissas pressupõe o papel preponderante dos membros das comunidades que estão próximas aos sítios na preservação. Ou seja, rechaça qualquer tipo de intervenção sem a participação dessas comunidades, que preparadas e equipadas convenientemente poderão assumir a gestão participativa, incluída a própria preservação.

A segunda premissa refere-se à impossibilidade de haver proteção sem o conhecimento do que deve ser protegido e, para isso, a pesquisa cientifica é fundamental e insubstituível. Nesse sentido, a presença constante de membros das comunidades nas equipes de pesquisas é essencial, assim como a execução de um 
programa de reuniões para apresentar as informações atualizadas e debater os passos a serem seguidos, proporcionando um âmbito de transparência e de confiança necessário para a execução do programa de atividades e a futura gestão.

Como terceira premissa, se postula que a conservação dos sítios arqueológicos não pode estar dissociada da esfera econômica e, por tanto, deve ser pensado sempre em retornos financeiros, melhoras materiais e benefícios sociais para os grupos que estão em contato com os sítios. Disto tudo, cabe deduzir que não pode haver preservação do acervo arqueológico (os sítios e seus conteúdos) sem que exista a compreensão e o aproveitamento correto, participativo e sustentável dele, por parte das comunidades próximas.

\section{AÇAÕES DE SENSIBILIZACÃo E CAPACITACÃO ARQUEOLÓGICA}

Como forma de iniciar e consolidar as relações com as comunidades dos seis municípios contemplados pelo projeto dos Circuitos Arqueológicos, se fez necessário um diálogo contínuo entre todos os agentes responsáveis pela pesquisa, salvaguarda e gestão (pesquisadores, instituições privadas e poder público) e os grupos das comunidades aos quais os locais arqueológicos se encontravam diretamente vinculados. A partir dessa postura igualitária foi possível a organização de um programa de ações voltadas, primeiramente, à sensibilização dos grupos no que tange ao valor simbólico e econômico dos monumentos arqueológicos e, depois, quanto ao destino dele, tanto no âmbito da preservação, quanto a da adequada gestão. 
Há algumas décadas, alguns pesquisadores vêm se debruçando sobre a importância de uma prática social, tendo os bens culturais como veículo de trocas de saberes que conduziriam a um movimento de ressignificação e utilização, que, constitui o embasamento da memória coletiva, essencial a qualquer tentativa de preservação e continuidade física, (Horta, 1999; Lopes, 2012).

Locais arqueológicos como monumentos e artefatos como documentos promovem os vínculos com o passado, que apesar de ser obviamente seletivo, provoca diversos efeitos marcantes, nas comunidades e sociedades contemporâneas. Assim são construídas narrativas que justificam a existência, história e aproveitamento desses espaços e objetos, coerentes com o conjunto de conhecimentos que as comunidades detenham.

Com essa perspectiva, foi possível desenvolver um processo contínuo de convivência caracterizado pelo respeito entre as partes (comunidades pesquisadores), com abertura para discussões e trocas de informações. Esse constante convívio esteva associado a uma interação entre diferentes indivíduos, numa inter-relação que foi estabelecendo-se no plano da reciprocidade, referendada pela existência harmônica, a tolerância pela diferença e o respeito pelo ambiente social e natural. Nesse cenário, o pesquisador é mais um aprendiz, que descobre no dia a dia, as explicações lógicas para o universo material e simbólico em que a comunidade está envolvida. 
$\mathrm{Na}$ relação com os pesquisadores do projeto e as comunidades locais, havia ao mesmo tempo, fontes emissoras, dos dois lados e receptora de experiências, também, de ambos os lados. Desse contexto, pode-se perceber a importância do feedback dos agentes envolvidos, pois criou-se uma profunda sintonia e responsabilidade para as tarefas a cumprir. Logo, essa reciprocidade, no âmbito do Projeto dos Circuitos Arqueológicos, redundou em uma transformação na postura conservadora da ação em campo, revelando uma atitude democrática de trocas de conhecimentos e participação ativa dos representantes comunitários.

No entanto, para que o trabalho com as comunidades fosse realmente significativo e promovesse a percepção e sensibilização sobre os locais arqueológicos foi indispensável que o pesquisador compartilhasse com os moradores locais (incluindo o poder público local), suas experiências de campo e laboratoriais, expressando conceitos, terminologias e metodologia apropriados para o seu trabalho e, ao mesmo tempo, as pessoas apresentassem as percepções do seu contexto social e cultural, indicando os elementos materiais e imateriais que deveriam ser considerados para um programa de preservação e gestão.

No caso do projeto dos Circuitos Arqueológicos, pôde-se dimensionar uma nova postura sobre a relação sobre os sítios arqueológicos e as comunidades, em que a concepção, está vinculada, principalmente, aos valores que a comunidade proporciona, especialmente no que concerne à interpretação e à outorga de significados. Nesse caso, considerando os locais com pinturas rupestres chapadense 
houve um reconhecimento do potencial de mobilização sensitiva e emocional, que poderia derivar em um sentimento de topofilia, necessário para a construção de uma memória coletiva.

O fato de abrir espaço para o tema da participação das comunidades no contexto de pesquisa arqueológica, proporcionou um convite à reflexão quanto a responsabilidade que assume o profissional arqueólogo e o cidadão não especialista no processo de fortalecimento e ressignificação da história local. A partir dessa premissa, o arqueólogo vê-se como vetor de geração de novas informações e de estímulos que promovem o sentimento de inclusão na construção de um processo histórico, em que indivíduos se sentem personagens partícipes. Percebe-se, então, sob esta nova ótica da Arqueologia, que o grande desafio da relação com as comunidades, não se limita à divulgação dos resultados arqueológicos, mas à utilização deles como elementos de diálogo para fomentar percepções, pensamentos e sensibilidades.

Ademais, como posicionamento da prática arqueológica comunitária, em todas as etapas desenvolvidas, houve a participação das comunidades, representadas por lideranças reconhecidas pelos grupos ou simplesmente cidadãos que dialogam ativamente e permanentemente com os pesquisadores acerca das decisões a serem tomadas no rumo dos estudos e quanto se refere ao destino dos materiais coletados e estudados. No caso do projeto dos Circuitos Arqueológicos, desde a realização dos encontros e oficinas arqueológicas, passando pelas atividades de campo, a 
presença das comunidades locais foi uma prerrogativa para a realização das ações previstas e de suma importância para o positivo resultado alcançado.

\section{REALIZAÇÃO DE ENCONTROS DE ARQUEOLOGIA}

Como forma de iniciar os primeiros contatos e sensibilizar os moradores dos seis municípios contemplados pelo projeto dos Circuitos Arqueológicos realizou-se encontros de Arqueologia em diferentes espaços comunitários, como escolas públicas e sedes de associações. Nesses encontros, as atividades desenvolvidas tiveram como característica a interação com as pessoas, onde a mola propulsora do evento foi a fala dos participantes que narraram as histórias locais e descreveram diferentes contextos culturais da região. Em cada narrativa sobre os locais onde moravam e as coisas que faziam, ficava claro que o indivíduo e o meio sociocultural eram indissociáveis, não só com relação à sua história pessoal, mas também em relação à história do grupo social. Coube a equipe de pesquisadores, registar as informações expostas pelos partícipes como dados que davam significado as suas vidas e que mostravam as potencialidades históricas dos seus municípios.

Durante as falas dos moradores, com suas narrativas e informações socioculturais, a equipe do projeto fez diversas abordagens reflexivas, incluindo no bojo da discussão o universo da Arqueologia e suas especificidades. A primeira dessas reflexões foi mostrar o conceito da ciência, seu objeto de estudo, seus objetivos e suas metodologias de trabalho. Foi exposto, de maneira bem geral, como sobrevém o trabalho do arqueólogo, explicando cada etapa e a importância delas para se 
chegar ao resultado final. Destacou-se como a pesquisa arqueológica é minuciosa e como é importante o envolvimento da comunidade em cada etapa realizada, considerando as ações de campo, de laboratório e da socialização dos resultados alcançados.

As outras reflexões dialogadas com os participantes dos encontros de Arqueologia tiveram um caráter informativo sobre diferentes estudos já realizados no estado da Bahia, mais especificamente na Chapada Diamantina. Foram apresentados os diferentes vestígios arqueológicos encontrados na região com a exibição de várias imagens de sítios de arte rupestre, artefatos líticos, cerâmicas pré-coloniais e a diversidade de materiais encontrados a partir da chegada dos portugueses. Ao mostrar esses diferentes testemunhos culturais, houve a confirmação por parte dos moradores sobre aa existência de vários objetos nas regiões dos municípios representados. Esse fato demonstra como a comunidade local é peça chave na identificação de sítios arqueológicos.

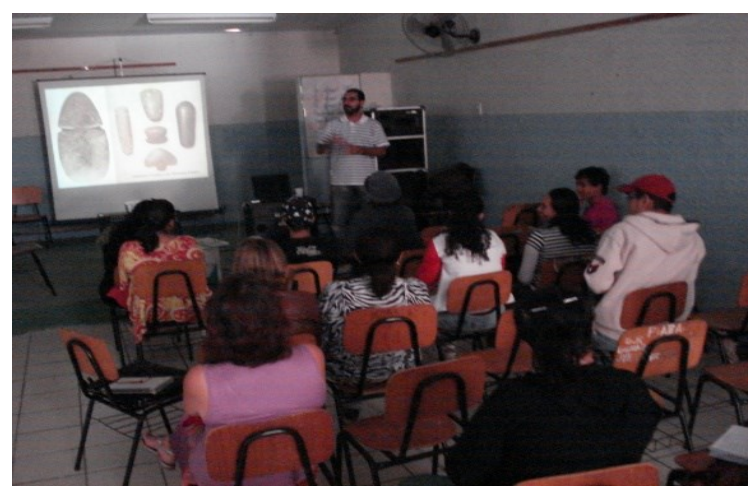

Figura 2: Encontros com as comunidades de Seabra. 


\section{REALIZAÇÃO DAS OFICINAS ARQUEOLÓGICAS}

Com o término dos encontros de arqueologia, teve início a etapa mais duradoura e integralista do Projeto dos Circuitos Arqueológicos: a realização das oficinas arqueológicas. Caracterizava-se por uma série de atividades (teóricas e práticas) objetivando a sensibilização e capacitação das pessoas na identificação, preservação e gestão dos locais arqueológicos, com ênfase, nos sítios de arte rupestre. Para a efetivação dessas ações foi instituído grupos de trabalhos compostos por diferentes representantes das comunidades locais, como professores, alunos, diversos líderes comunitários e funcionários públicos municipais.

As primeiras ações metodológicas, desenvolvidas nas oficinas arqueológicas, consideraram uma sequência de atividades que contemplavam conteúdos e estratégias de interação com o público. O objetivo desse trabalho inicial, foi compreender o contexto sociocultural das localidades, sob o olhar dos moradores, ampliando as informações coletadas durante a realização dos encontros de arqueologia. Nesse sentido, os trabalhos foram conduzidos em conjunto com os moradores, tendo como referencial os conhecimentos e saberes populares que tinham sobre a região em que moravam. Como forma de materializar essas informações, as pessoas se dividiram em grupos e elaboraram painéis com imagens que ilustravam suas realidades, que foram socializados entre todos.

Concluída a primeira etapa das oficinas arqueológicas, que teve como foco o olhar dos moradores locais sobre sua própria região, teve início uma sequência de 
atividades direcionadas para a prática arqueológica, caracterizadas pela identificação e registro de sítios de arte rupestre e outra voltada para escavações arqueológicas em três sítios com pinturas. A realização das duas ações, com características teóricas e práticas, tinham como finalidades facilitar os trabalhos de campo, onde os grupos iriam registrar, in loco, os locais arqueológicos.

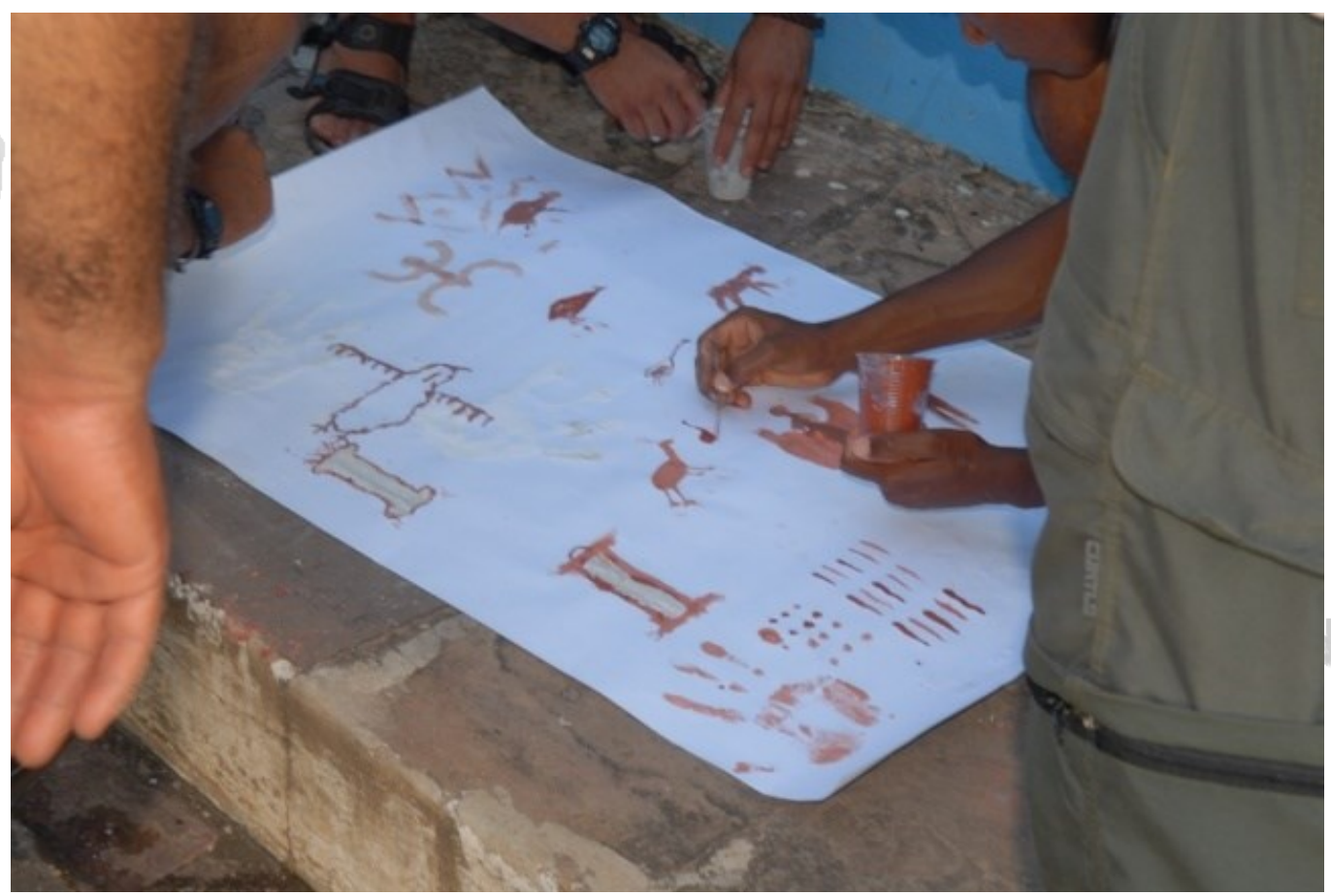

Figura 3: Oficinas Arqueológicas: elaboração de painéis com a temática dos sítios de pinturas identificados na região da Chapada Diamantina. 


\section{IDENTIFICAÇÃO E REGISTRO DE SÍTIOS RUPESTRES}

Durante todo o período do Projeto dos Circuitos Arqueológicos foi realizado a identificação e o registro de vários sítios de arte rupestre dentro do universo territorial que engloba os seis municípios participantes. Para a realização desses mapeamentos, os representantes das comunidades passaram por uma etapa de preparação e capacitação, com preleções teóricas e práticas sobre o manuseio dos equipamentos (máquinas fotográficas, GPS e bússolas) e, principalmente, a coleta das informações ambientais e arqueológicas, a partir de uma ficha documental.

Para cada sítio de arte rupestre registrado, houve uma ficha de campo com importantes informações sobre o contexto em que ele estava inserido e outras mais específicas sobre os painéis de pinturas e gravuras. A etapa que sucedeu o mapeamento foi a organização dessas fichas documentais e de todo acervo fotográfico em uma base de dados que foi disponibilizado para o IPAC e para diferentes Instituições dos seis municípios envolvidos no Projeto. Durante as atividades de campo, a equipe do projeto, junto com as comunidades locais, fez o registro de 34 sítios rupestres e de alguns locais que podem ser identificados pela potencialidade histórica e cultural. 


\begin{tabular}{|c|c|c|}
\hline Município & Qtd. de Sítios & Nome dos Sítios \\
\hline Seabra & 13 & $\begin{array}{c}\text { Agreste } \\
\text { Alagadiço } \\
\text { Aguada } \\
\text { Areiao } \\
\text { Brejinho } \\
\text { Carreiro do Cercadinho } \\
\text { Curral do Sal } \\
\text { Morrinho do Cascudo } \\
\text { Pedra do Tapuia } \\
\text { Pinta do tapuia } \\
\text { Sapeca } \\
\text { Toca dos Tapuias } \\
\text { Serra das Tapuias }\end{array}$ \\
\hline Morro do Chapéu & 9 & $\begin{array}{c}\text { Lagoa da Velha } \\
\text { Toca da Figura } \\
\text { Toca do Pepino } \\
\text { Bocana } \\
\text { Espinheiro } \\
\text { São Francisco da Palmeira } \\
\text { Tapera } \\
\text { Tamboril } \\
\text { Poço das Traíra }\end{array}$ \\
\hline Palmeiras & 3 & $\begin{array}{l}\text { Matão de Cima } \\
\text { Matão de Baixo } \\
\text { Serra Negra }\end{array}$ \\
\hline Iraquara & 5 & $\begin{array}{c}\text { Lapa do Sol } \\
\text { Torrinha I } \\
\text { Torrinha II } \\
\text { Pratinha } \\
\text { Santa Marta } \\
\end{array}$ \\
\hline Lençóis & 4 & $\begin{array}{l}\text { Serra das Paridas I } \\
\text { Serra das Paridas II } \\
\text { Serra das Paridas III } \\
\text { Serra das Paridas IV }\end{array}$ \\
\hline
\end{tabular}

Tabela 1. Sítios registrados durante o Projeto dos Circuitos Arqueológicos. 
Como a premissa do projeto sempre foi a integração com as comunidades, que engloba também o poder público, houve a iniciativa em buscar parceria com as autoridades municipais das seis cidades contempladas pelo projeto. Essa conexão entre os parceiros municipais foi muito significativa para o desenvolvimento das propostas previstas. Cada secretário, que participou das reuniões que foram realizadas no início das ações, exerceu o compromisso inicial que foi firmado: incentivar a participação de representantes comunitários nas atividades do projeto (encontros e oficinas) e de campo (mapeamento de sítios rupestres e visitas in loco), organizar sua logística e contribuir durante as etapas de mapeamento e da elaboração dos itinerários turísticos.

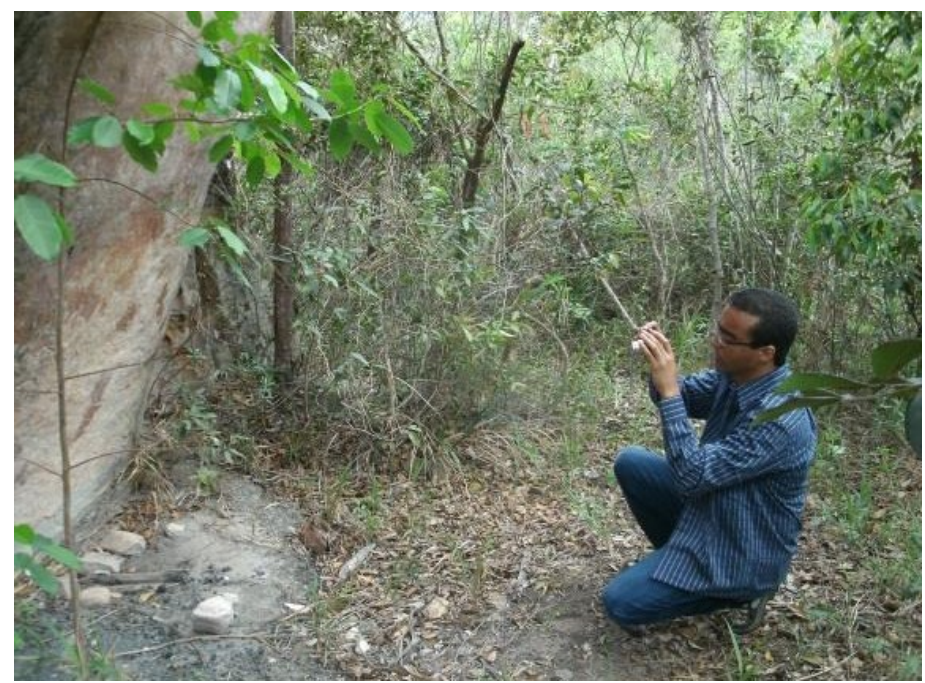

Figura 3: Mapeamento e o registro de sítios de pinturas, no município de Palmeiras, com a participação da comunidade local. 


\section{VISITAS DE CAMPO}

Intercalando o mapeamento de sítios arqueológicos e como forma de ampliar as atividades das oficinas que estavam sendo realizadas no âmbito do projeto, foi feito uma ação que contemplava a visita guiada em sítios de arte rupestre, conhecidos por arqueólogos, mas desconhecidas para a maioria das comunidades locais. Os trabalhos de campo foram desenvolvidos com a participação de um público bem heterogêneo, formado por professores, alunos e representantes municipais de diversas atuações profissionais. Os participantes tiveram a oportunidade de conhecer e reconhecer o potencial rupestre da Chapada Diamantina e identificar locais arqueológicos da região em que vivem, tendo a oportunidade de visualizar painéis gráficos que só conheciam nas páginas dos livros didáticos.

O objetivo das visitas de campo não estava calcado no mero passeio de turismo ou de lazer. Teve o foco direcionado para uma aprendizagem dinâmica (Campos, 1987), onde foi considerado que as experiências vivenciadas em locais arqueológicos têm um papel determinante para fomentar o conhecimento prévio dos visitantes e influenciar no desenvolvimento de conhecimentos posteriores. Nesse sentido, os ambientes com pinturas rupestres podem ser locais de entretenimento, mas é também, e talvez o seja antes de tudo, um espaço para se pensar pesquisa, de compreender contextos culturais e refletir sobre as diversas possibilidades de preservação e gestão desses territórios. 
Nesses espaços arqueológicos, o conhecimento se constrói no embate entre sujeito e objeto e a participação de um profissional especializado é de fundamental importância. A parceria entre o pesquisador e o público visitante é muito importante, pois alia diferentes saberes em benefício do grupo: cada um contribui com suas experiências e conhecimentos, gerando um ambiente propício à troca. Outro ponto a ser considerado é a oportunidade das comunidades locais conhecerem diferentes registros do passado como forma de aprendizado histórico, reflexão, entretenimento e convivência social.

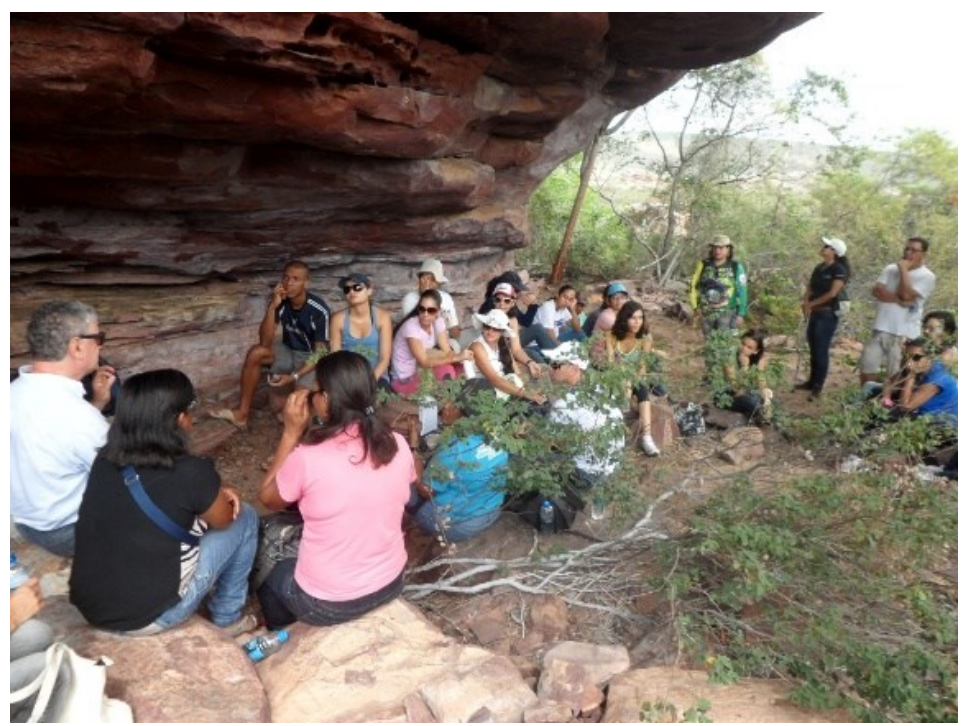

Figura 4. Visitas de campo: Atividade in loco, em sítios rupestres, com a participação das comunidades locais.

\section{ESCAVAÇÕES ARQUEOLÓGICAS}

Uma das etapas mais integradora do projeto dos Circuitos Arqueológicos, que assinalou a relação entre a equipe de pesquisa e as comunidades foi a escavação

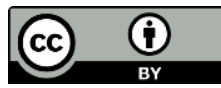


arqueológica, pois, além de contar com a participação de moradores locais, suscitou diversas possibilidades para o uso sustentável dos espaços pesquisados, quanto as discussões sobre as principais medidas de proteção para os sítios de arte rupestre. As intervenções de campo ocorreram em quatro locais que já estavam sendo estudados do ponto de vista gráfico: Serra das Paridas I, em Lençóis, Lagoa da Velha, em Morro do Chapéu, Matão de Cima, em Palmeiras, e Lapa do Sol, em Iraquara.

Os critérios de escolha desses sítios de arte rupestre foram de várias ordens, sendo a primeira delas relacionada ao potencial informativo dos espaços, considerando:

a) O reconhecimento da existência de solos de deposição natural e antrópica, aptos para a escavação;

b) A verificação em superfície de não ter havido perturbações pósdeposicionais consideráveis;

c) A apresentação nos painéis dos sítios de diferentes temáticas gráficas que permitam realizar uma amostragem de várias linguagens gráficas;

d) A constatação de bom grau de conservação das pinturas rupestres;

e) A identificação de elementos gráficos que possam ser emblemáticos das relações dos estilos entre áreas do Nordeste brasileiro;

O segundo aspecto refere-se às condições favoráveis ao acesso aos sítios, seja acessibilidade para os aspectos operacionais das escavações, seja para a visitação pretendida, objeto do Projeto. O terceiro critério considera a aceitação, por parte dos proprietários dos terrenos onde se encontram os sítios, de serem incluídos nos circuitos de visitação, ou que implica necessariamente, a autorização para que a equipe de arqueólogos possa realizar as pesquisas. 
Os trabalhos de campo primaram pelo desenvolvimento de práticas arqueológicas e suas hipóteses propostas, articuladas com os conhecimentos locais do ambiente circundante, colocando os contextos pesquisados em discussão com os moradores desses locais e dando voz aos saberes tradicionais, comumente apagados no decorrer da construção do discurso científico. Neste sentido, a investigação cientifica se focou, também, nas interpretações dadas pelas comunidades que convivem com os sítios de pinturas rupestres, a partir de situações vividas, experiências e informações adquiridas. As evidências arqueológicas são únicas, mas a variedade de interpretações, significações e percepções são variadas, dependendo do olhar atribuído. O registro arqueológico possui relevância tanto para o conhecimento e entendimento do passado quanto do presente.

As escavações arqueológicas realizadas nos quatro sítios de arte rupestre, foram mais do que apenas um estudo investigativo que se propõe a explanar sobre cronologias dessas ocupações pretéritas e apresentar seus modos de vida. As intervenções de campo se apresentaram como uma tentativa de interlocução entre duas realidades territoriais distintas, ao promover uma reflexão entre discursos que, frequentemente, são percebidos como dissociados e até mesmo concorrentes: o da ciência arqueológica, por meio da construção do conhecimento, a partir dos métodos científicos e o popular, que representa a forma como os moradores locais percebem seu território e o que o compõe. Não obstante, essa percepção altera os modos de usos do espaço e, consequentemente, pode promover a preservação e gestão dos locais arqueológicos. 


\section{INTEGRAÇÃO PESQUISADORES E COMUNIDADE CHAPADA DIAMANTINA}

Em todas as atividades desenvolvidas no âmbito do projeto dos Circuitos Arqueológicos, as presenças e participações das comunidades locais foram contínuas e efetivas. Nos encontros de arqueologia, nas oficinas arqueológicas e nos trabalhos de campo, as indagações dos moradores eram pertinentes aos temas arqueológicos apresentados discutidos e, sempre contribuíam com informações sobre suas realidades socioculturais e as mais diversas histórias e narrativas referentes aos sítios de arte rupestre identificados na região.

A participação efetiva dos moradores em todas as ações do projeto, as inúmeras histórias locais que foram contadas e registradas, fizeram com que as práticas arqueológicas fossem desenvolvidas de forma integrada e respeitosa. Criou-se um ambiente em que os conhecimentos científicos se misturaram com os saberes populares e o resultado dessa integração de pensamentos, foi o reconhecimento dos monumentos arqueológicos da região como lugares do passado, mas que são espaços que foram sendo ocupados e modificados ao longo do tempo, criando características próprias e que podem ser resignificados e utilizados no presente.

Ademais, um dos principais resultados da integração entre os pesquisadores do projeto dos Circuitos Arqueológicos e as comunidades locais, foi a constituição de um grupo de trabalho denominado de Agentes Patrimoniais, onde formou-se uma unidade heterogênea, muito representativa e dinâmica. São representantes 
comunitários de diferentes segmentos das sociedades dos seis municípios participantes e que desde então vem desenvolvendo ações direcionadas para a preservação e gestão dos bens materiais e imateriais, principalmente, os sítios de arte rupestre.

A figura do Agente Patrimonial foi idealizada, pelo Grupo Bahia Arqueológica durante o desenvolvimento dos seus projetos, para designar a qualquer pessoa que zele e promova a preservação, com estudos e gestão participativa, de sítios arqueológicos pré-coloniais, coloniais e pós-coloniais no território do Estado da Bahia e que atue de forma permanente. Aplica-se, assim, à pessoa que sensível aos significados históricos e identitários de que podem estar imbuídos os sítios e materiais coletados neles, dedica-se de forma voluntária a atuar, individual ou coletivamente, em atividades e programas que estejam centrados no patrimônio cultural de uma determinada região. Assim sendo, a capacitação técnica dos Agentes Patrimoniais, por parte de especialistas, não fará senão proporcionar as ferramentas que contribuirão a maximizar suas ações ou, então, a se incorporar a programas institucionais que por ventura sejam projetados. Portanto, com esta denominação, Agentes Patrimoniais, ficam destacadas a função e motivações, e reconhecidas as ações e os princípios motivadores, mesmo que não o seja com uma titulação da estrutura oficial.

No caso do projeto do Circuitos Arqueológicos a realização integrada entre pesquisadores e comunidades, consolidou o grupo de agentes patrimoniais de cada 
um dos seis municípios. Em cada atividade efetivada e concluída, ampliava o interesse de pessoas envolvidas pela proposta e que firmava sua participação em prol da identificação, da preservação e da gestão de sítios de arte rupestre na região. A intensidade da relação estabelecida por parte da equipe do projeto com as comunidades e com o staff administrativo de alguns dos seis municípios chapadenses pode se medir pelo grau de participação que houve durante a realização de dois importantes eventos: o encontro de Arte Rupestre, realizado em Lençóis em agosto de 2010 e o I Encontro de Agentes Patrimoniais da Chapada Diamantina, que também, aconteceu no município de Lençóis em dezembro de 2013.

O Encontro de Arte Rupestre foi um evento nacional, que unia o V seminário de Arte Rupestre da UFBA e a III reunião da Associação Brasileira de Arte Rupestre (ABAR), onde compareceram os pesquisadores mais destacados que trabalhavam no Brasil com a temática de arte rupestre. Contou-se, por exemplo, com a presença de Niéde Guindon, da Fundação Museu do Homem Americano, do Parque Nacional da Serra da Capivara (Piaui), de Anne Marie Pessis, da UFPE, Gabriela Martin, também da UFPE, Agueda Vilhena-Vialou e Denis Vialou, do Museu de História Natural de Paris, mas que trabalham em Mato Grosso, entre outros. Do ponto de vista científico a reunião constituiu, deveras, um marco nesse campo da arqueologia brasileira.

Porém, o que mais chamou a atenção foi a brilhante participação dos representantes das comunidades. A programação do evento previa módulos em que os não 
especialistas tiveram oportunidade de mostrar o patrimônio arqueológico de cada município e discutir a situação atual dos sítios, assim como propor alternativas de utilização correta, que fosse de benefício compartilhado por todos. Ademais, muitos dos representantes tiveram a oportunidade de conversar diretamente com os pesquisadores de outros estados e fazer suas perguntas, dirimir suas dúvidas e mostrar sua capacidade de observação e reflexão.

Pesquisadores convidados, ao final do evento, se pronunciaram manifestando sua admiração pelos representantes das comunidades estarem manejando a terminologia e os conceitos adequados e reconheceram a importância da dimensão social que uma pesquisa arqueológica, centrada em arte rupestre, pode chegar a alcançar.

O I Encontro de Agentes Patrimoniais da Chapada Diamantina deu início à construção de uma rede social de pessoas interessadas e compromissadas na pesquisa, preservação e gestão de locais com pinturas e gravuras rupestres, como forma fortalecer as iniciativas individuais ou coletivas. Como dinâmica do encontro estavam programadas sessões com apresentações de todas as experiências, em que uma pessoa ou um grupo exponham acerca do patrimônio com que trabalham, as ações projetadas e realizadas, os problemas e sugestões de solução. Acompanhando as falas eram apresentadas imagens dos sítios a que as ações se referem. Nesse evento, as apresentações e discussões permitiram elaborar um mapa de ocorrências de sítios, de pessoas ou equipes atuantes. Ao mesmo tempo, fomentou um locus de 
convergência de informações para preparar diretrizes de trabalho a curto e médio prazo.

Por conseguinte, o Encontro de Agentes Patrimoniais da Chapada Diamantina constituiu uma das últimas ações do programa de formação e capacitação, que fazia parte do Projeto dos Circuitos Arqueológicos. Cumpriu seu objetivo de reunir os agentes capacitados dos seis municípios contemplados para discutir sobre os sítios com arte rupestre da região apontando inciativas que merecem ser destacadas, apoiadas, incentivadas, orientadas e divulgadas.

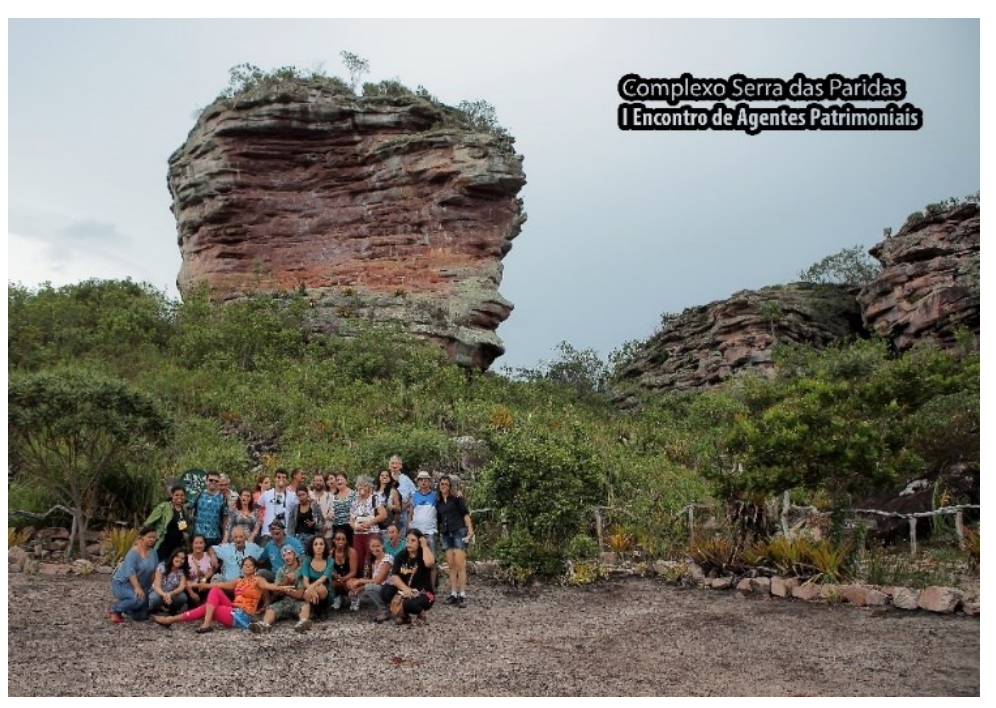

Figura 5: Participantes do Seminário. Encontro dos Agente Patrimoniais Auditório Afrânio Peixoto, município de Lençóis. 


\section{CONCLUSÕES}

A identificação e registro dos 34 sítios rupestres, durante o mapeamento de campo, confirma a potencialidade arqueológica da região da Chapada Diamantina, constituindo um significativo patrimônio e nos desafia a refletir sobre as ações que podem ser realizadas para uma efetiva preservação desses ambientes particulares da nossa história e viabilizar itinerários de visitação, de maneira racional e sustentável, trazendo benefícios para as comunidades que residem em seu entorno. A realização das atividades com as comunidades locais, a partir dos encontros de arqueologia, das oficinas arqueológicas, os trabalhos de campo e seus desdobramentos teve um resultado muito satisfatório. A avaliação positiva, por parte dos participantes do projeto de cada município, demonstra o interesse da comunidade em desenvolver trabalhos em conjunto com as práticas arqueológicas, confirmando que a relação entre pesquisadores e as pessoas das localidades onde os sítios rupestres se encontram, pode avalizar a preservação do patrimônio arqueológico e fomentar projetos e programas de turismo sustentável.

As experiências vivenciadas no âmbito do projeto dos Circuitos Arqueológicos, demonstraram que trabalhar com o patrimônio arqueológico exige o envolvimento das comunidades, fomentado por ações educativas para a valorização do patrimônio regional e, ainda, sua participação no desenvolvimento de programas para a gestão do patrimônio cultural. Os exemplos apresentados no projeto mostram sempre a participação efetiva das comunidades locais, atuando em conjunto com os 
pesquisadores e, consequentemente, os resultados apontam para a valorização e da identidade com o patrimônio arqueológico, que possibilitou ações de preservação de alguns sítios rupastes. Dessa maneira, pode-se pensar que as comunidades se tornaram vigilantes e protetoras de diferentes legados culturais.

A participação da comunidade local é de fundamental importância para a obtenção de resultados positivos no processo de planejamento dos projetos de arqueologia. Não há dúvida que nas pesquisas arqueológicas onde ocorrer a participação efetiva das comunidades locais, haverá a valorização e a preservação dos sítios arqueológicos. No caso do projeto dos Circuitos Arqueológicos, ficou evidente que os trabalhos realizados em conjunto com os moradores que residem nas proximidades dos sítios de arte rupestre, desenvolvido de forma processual e integrada, foi fundamental para garantir a proteção dos espaços culturais e mostrou a importância de se respeitar e valorizar os conhecimentos populares durante a elaboração de mecanismos de preservação e gestão.

$\mathrm{Na}$ atualidade, pode-se verificar a eficácia da ação dos Agentes Patrimoniais na Chapada Diamantina, vem sendo responsável pela identificação e registro de vários sítios arqueológicos e inúmeras iniciativas locais vem garantindo a proteção dessas áreas, principalmente, no acompanhamento de vários projetos de empresas eólicas e solares, alertando e fiscalizando as atividades de estudos ambientais e instalações desses empreendimentos. Ademais, a existência dos agentes patrimoniais corrobora com as premissas que vem sendo discutidas ao longo do artigo e que afirmam e 
demostram a significância da integração entre pesquisadores e comunidades no desenvolvimento das práticas arqueológicas.

Em suma, deve-se considerar como fundamental reconhecer e valorizar os aspectos culturais, históricos e sociais das comunidades através das possibilidades de conexão com bens arqueológicos para construir uma compreensão do passado, definir uma estratégia para enfrentar o presente, e quem sabe avaliar os principais aspectos para planejar o futuro. Pode-se dizer que decorre daí as dinâmicas de construção da identidade seja no âmbito local, regional ou nacional. Assim cabe articular as atividades programáticas a fim de lançar algumas sementes para a preservação da herança cultural em suas múltiplas dimensões de significado. Preservar, no sentido aqui defendido, expressa um conjunto de atitudes e ações desenvolvidas por todos os envolvidos (poder público, comunidade, escola, etc) com o objetivo de cuidar, recuperar e conservar o os territórios arqueológicos. A preservação tende a garantir acesso aos espaços arqueológicos, bem como ao acervo de conhecimentos e experiências vinculado ao universo envolvido. Sendo assim, as ações de preservação deverão contribuir para o fortalecimento da cidadania e identidade. 


\section{REFERENCIAS BIBLIOGRÁFICAS}

BOADO, Felipe Criado. Arqueológicas. La Razón Perdida - La Construcción de La Inteligencia Arqueologica. Capítulo 1: La Tradición Arqueologica: arqueologia y modernidade. Bellaterra Arqueologia. Barcelona, 2012.

CAMPOS, D. M. de S. Psicologia da aprendizagem. Petrópolis: Vozes, 1987.

COELHO, M. T; JOSÉ, E. A. Problemas de aprendizagem. São Paulo: Ática, 1999.

ENDERE, M. L., \& ZULAICA, M. L. (2015). Socio-cultural sustainability and "Buen Vivir" (Good Living) at heritage sites: assessment of the Agua Blanca case, Ecuador. Ambiente \& Sociedade.

ETCHEVARNE, Carlos. Projeto Circuitos Arqueológicos de Visitação da Chapada Diamantina. Convenio IPAC/UFBA. Salvador. 2010.

ETCHEVARNE, Carlos. Relatório Final do Projeto Circuitos Arqueológicos de Visitação da Chapada Diamantina. Convenio IPAC/UFBA. Salvador. 2015.

GRIFFITH, C. S., \& GRIFFITH, L. M. (2012). Partnerships in Archaeotourism: the Future of Cueva Borbon, Dominican Republic. Chungara- Revista de Antropologia Chilena, 44(3), 523-532. https://doi.org/10.4067/S0717-73562012000300014.

Consultado em 2020.

HORTA, Ma de Lourdes; GRUNBERG, Evelina e MONTEIRO, Adriane: Guia Básico de Educação Patrimonial. Brasília: Instituto do Patrimônio Histórico e Artístico Nacional, Museu Imperial, 1999.

LOPES, A. N. (2012). “O CISEA, o ISPSN e o Patrimônio Cultural: Subsídios para uma Estratégia de Intervenção Cultural”. Revista do Centro de Investigação Sobre Ética Aplicada Sol Nascente, Editorial n ${ }^{\circ} 2$.

LUMBRERAS, J.G. La Arqueologia como Ciencia Social. Ediciones Piesa: Lima, Peru 1981.

VAQUERIZO, Desiderio. Arqueología Pública, O El Uso Social Del Patrimonio. Revista Otarq. Vol. 2 2017, pp. 251-284. 